\title{
Anemia and Diabetes
}

\author{
G. Deray ${ }^{a}$ A. Heurtier ${ }^{b}$ A. Grimaldi ${ }^{b}$ V. Launay Vacher ${ }^{a}$ C. Isnard Bagnis ${ }^{a}$ \\ Departments of a Nephrology and ${ }^{b}$ Diabetology, Hôpital Pitié, Salpêtrière, Paris, France
}

\section{Key Words}

Anemia · Diabetes · Erythropoietin · Hemoglobin • Renal failure

\begin{abstract}
World Health Organization statistics identify 150 million people with diabetes mellitus worldwide and suggest that this figure may double by 2025 . In countries with a western lifestyle, the number of patients admitted for renal replacement therapy with diabetes as a co-morbid condition has increased significantly up to three to four times in a period of 10 years. Diabetes and renal failure are thus tightly linked diseases, and so is anemia. However, whether anemia may be worsened and/or directly, at least in part, caused by diabetes is not clearly elucidated yet. In this article, we review the prevalence, pathophysiology and consequences of anemia in diabetic patients.
\end{abstract}

Copyright (c) 2004 S. Karger AG, Basel

\section{Introduction}

End-stage renal disease (ESRD) in diabetes mellitus patients has been called a 'medical catastrophe' of worldwide dimension [1]. World Health Organization statistics identify 150 million people with diabetes mellitus worldwide and suggest that this figure may double by 2025 .
In countries with a western lifestyle, the number of patients admitted for renal replacement therapy with diabetes as a co-morbid condition has increased significantly up to three to four times in a period of 10 years [2]. Consequently, diabetes is the single most common cause of endstage renal disease and therefore the most common cause of renal anemia. In this article, we review the prevalence, pathophysiology and consequences of anemia in diabetic patients.

\section{Prevalence of Anemia in Diabetic Patients}

Patients with diabetes suffer the consequences of impaired renal function earlier in the course of their disease than do their non diabetic counterparts [3-7]. In diabetic nephropathy $(\mathrm{DN})$, anemia tends to be more severe than in non-diabetic renal disease and occurs at an earlier stage of the disease. However, because most patients with DN have little overt renal impairment, primary care physicians or endocrinologists are often the first-line health care providers and may not be aware of the critical importance of screening for anemia in this population. Therefore, anemia may often be unrecognized or untreated.

Several studies based on a small number of patients with overt nephropathy, have suggested that prevalence of anemia is higher in diabetic patients. Bosman et al. [3] compared 27 type 1 diabetes patients with DN (defined as having persistent proteinuria, a serum creatinine

\begin{tabular}{ll}
\hline KARGER & @ 2004 S. Karger AG, Basel \\
0250-8095/04/0245-0522\$21.00/0 \\
$\begin{array}{l}\text { Fax +4161306 1234 } \\
\begin{array}{l}\text { E-Mail karger@karger.ch } \\
\text { www.karger.com }\end{array}\end{array}$ & $\begin{array}{l}\text { Accessible online at: } \\
\text { www.karger.com/ajn }\end{array}$
\end{tabular}

Dr. Corinne Isnard Bagnis

Service de Nephrologie

Hôpital Pitié, Salpêtrière

FR-75013 Paris (France)

Tel. +3314217 7227, Fax +33 14217 7914, E-Mail corinne.bagnis@psl.ap-hop-paris.fr 
$<180 \mu \mathrm{mol} / 1$ and retinopathy) with 26 non-diabetic patients with glomerulonephritis and persistent proteinuria. No significant difference was observed between the two groups at baseline. Anemia was present in 13 of the 27 diabetic patients (hemoglobin $10.6 \pm 0.9 \mathrm{~g} / \mathrm{dl}$ ) in marked contrast to none of the glomerulonephritis patients (hemoglobin $13.7 \pm 1.4 \mathrm{~g} / \mathrm{dl} ; \mathrm{p}<0.05)$.

In another study by Inomata et al. [4], 13 patients with overt nephropathy and normal renal function were followed for a mean of 26 months. Hemoglobin, endogenous erythropoietin $(\mathrm{EPO})$ and $\mathrm{Hb} \times \mathrm{EPO}$ values gradually decreased along with advancing stages of nephropathy. Furthermore, 6 patients with rapidly decreasing renal function showed significantly lower initial EPO and $\mathrm{Hb}$ $\times$ EPO values compared with 7 patients with stable renal function $(\mathrm{p}<0.01)$. These data suggest that renal abnormalities, possibly interstitial fibrosis may play a role in the pathophysiology of anemia in diabetes. They concluded that $\mathrm{EPO}$ and $\mathrm{Hb} \times \mathrm{EPO}$ values may provide new data regarding the severity of DN especially tubulointerstitial damage.

Ishimura et al. [5] have compared 19 patients with type 2 diabetes with 21 non-diabetic controls, matched for gender, age and serum creatinine. They have shown that the mean hemoglobin concentration was significantly lower in diabetic patients, and multivariate analysis established that diabetes was an independent risk factor. These results comfort the observation made by Dikow et al. [6] that many outpatients followed at their outpatient clinic had unexpected low hemoglobin values in relation to their level of endogenous creatinine clearance.

Kazmi et al. [7] have performed a retrospective cohort study to identify risk factors associated with severe anemia in 604 adult patients with elevated serum creatinine levels. Univariate logistic regression analysis showed that at age 65-74 years, hypertension, higher serum creatinine level, higher calcium phosphorus product and diabetes were significantly associated with severe anemia, defined as a pretherapeutic hematocrit value $<30 \%$ at anytime during the study. However, none of these studies were large enough to lead to consistent recommendations.

In contrast, in the Predialysis Survey of Anemia Management Study [8], the association between hemoglobin level and creatinine clearance rate was similar for diabetic and non-diabetic patients who were not treated with human recombinant erythropoietin (rHuEPO). Furthermore, in a prospective study including 403 predialysis patients, the proportion of patients with polycystic kidney disease or with diabetes mellitus was similar whether patients were treated or not with rHuEPO [9]. Recently, the first large-scale systematic survey assessing prevalence and predictors of anemia (a cross-sectional survey of 820 patients) has been performed in diabetic patients without nephropathy [10]. Sixty-one percent of the patients were normoalbuminuric, $27 \%$ had microalbuminuria and $12 \%$ had macroalbuminuria. Only $5 \%$ of the patients had heavy proteinuria ( $>1 \mathrm{~g} /$ day). The mean estimated glomerular filtration rate (GFR) was $75.7 \pm 1.3 \mathrm{ml} / \mathrm{min} /$ $1.73 \mathrm{~m}^{2}$ for men and $72.1 \pm 1.4 \mathrm{ml} / \mathrm{min} / 1.73 \mathrm{~m}^{2}$ for women.

Thirty percent had an estimated GFR $<60 \mathrm{ml} / \mathrm{min} /$ $1.73 \mathrm{~m}^{2}$. In addition, approximately half of the patients with diabetes in the study had both normoalbuminuria and a GFR $>60 \mathrm{ml} / \mathrm{min} / 1.73 \mathrm{~m}^{2}$ making this survey more representative of the overall population of diabetic patients. A total of 190 patients $(23 \%)$ had unrecognized anemia (hemoglobin $<12 \mathrm{~g} / \mathrm{dl}$ for women and $<13 \mathrm{~g} / \mathrm{dl}$ for men). This prevalence was two to three times that of the general population with the same GFR and similar iron store levels. This is consistent with the National Health and Nutrition Examination Survey (NHANES) data showing an adjusted odd ratio of 1.7 for anemia in type 2 diabetes [11]. Patients with persistent microalbuminuria had 4 times and patients with macroalbuminuria $>12$ times the risk of anemia compared to normoalbuminuric subjects. Impaired renal function (GFR $<60 \mathrm{ml} / \mathrm{min} /$ $1.73 \mathrm{~m}^{2}$ ) was associated with an increased risk of anemia (almost 11 times higher), i.e. a risk similar to patients with macroalbuminuria. Another cross-sectional audit designed to assess the prevalence and consequences of anemia in type 2 diabetic patients was recently published [12]. A full blood count was obtained in addition to routine testing in a cross-sectional survey of 2,125 diabetic outpatients. Median duration of diabetes was 10 years. The prevalence of elevated albuminuria varied between 27 and $43 \%$ in the three centers. Evidence of moderately impaired renal function (creatinine clearance $<60 \mathrm{ml} /$ $\min / 1.73 \mathrm{~m}^{2}$ ) was present in about one third of the patients. One of 5 patients had anemia, according to the World Health Organization guidelines (men <130 g/l; women $<120 \mathrm{~g} / \mathrm{l})$. Renal function measured as creatinine clearance was the strongest predictor of anemia. A significant association between creatinine clearance and the prevalence of anemia was also found in patients with a serum creatinine within the normal range.

It should be outlined that from the point of view of diabetic patients themselves, anemia is an unknown complication of their disease. In a pan-European study, patient's level of awareness and understanding of anemia and of other complications of diabetes mellitus were 
assessed. Only $32 \%$ of responders had been given information about anemia, although $83 \%$ had heard about anemia and only $14 \%$ attributed anemia to diabetes [13]. Raising awareness of anemia in diabetic patients is therefore of importance for the health care team.

\section{Pathophysiology of Anemia in Diabetic Patients}

EPO release by renal cells has been shown to be modulated by kidney splanchnic innervation. Indeed, renal denervation in animal models led to a loss of EPO production in response to hypoxic stimuli $[14,15]$. Furthermore, EPO deficiency has recently been observed in anemic type 1 diabetic patients with severe symptomatic diabetic autonomic neuropathy [16-18].

In Bosmans' study [3], involving a small cohort of patients, the serum EPO levels in anemic diabetic patients were found to be inappropriately low compared to the values observed in a control group of iron deficiency anemic subjects. In comparing the regression lines for the whole DN group with those of the non-anemic and anemic control groups, they found a difference in the slope of the logarithm of EPO values in relation to hemoglobin level when allowing non-parallel regression lines in the model [3]. It has thus been postulated that EPO deficiency in these patients may be caused at least in part by efferent sympathetic denervation of the kidneys leading to the loss of appropriate production of EPO in the presence of damaged producing fibroblasts in the renal cortex. This is supported by observations [16] that EPO-deficient anemia can occur prematurely in patients with type 1 diabetes and diabetic nephropathy, even before the onset of advanced renal failure. However, transplanted kidneys, which are also denervated, seem to be able to produce normal levels of EPO.

A reduced number of specific erythropoietin synthesizing interstitial cells and impairment of the regular processes enabling oxygen sensing through hypoxia-inducible transcription factor- $1 \alpha$ (HIF-1 $\alpha)$ secondary to interstitial fibrosis or vascular lesions are the main factors involved in anemia in diabetes. Other mechanisms may involve cytokine-induced EPO synthesis inhibition [20], hyporeninemia [21], urinary loss of EPO (in patients with nephritic range proteinuria) [22] glycation of the EPO receptor by or secondary to hyperglycemia. It has been suggested that the widespread use of angiotensin-converting enzyme (ACE) inhibitors in diabetes, particularly in patients with high urinary albumin level or renal impair- ment, may contribute to a reduction in hemoglobin levels [11]. Recent evidence fails to support any significant link between ACE inhibitor use and hemoglobin levels.

\section{Anemia and Diabetic Organ Damage}

There is considerable evidence that anemia exacerbates severity and impairs outcome of peripheral small vessel disease in diabetic patients and that rHuEPO therapy may prevent or reverse these complications.

\section{Retinopathy}

Subjects with normocytic anemia have an increased risk of retinopathy and more often exhibit severe lesions. In a cross-sectional survey involving 1,691 diabetic patients, a two fold increased risk of retinopathy was reported in patients with hemoglobin less than $12 \mathrm{~g} / \mathrm{dl}$ [23]. The severity of retinopathy was correlated with the severity of anemia; those with hemoglobin less than $12 \mathrm{~g} / \mathrm{dl}$ had a 5-fold increased risk of pre-proliferative or proliferative retinopathy compared with those with higher hemoglobin levels. Similarly, the Early Treatment Diabetic Retinopathy Study has reported anemia to be an independent risk factor for the development of high-risk proliferative diabetic retinopathy [24]. Indeed, in some cases, an improvement in retinopathy with anemia treatment in patients with diabetes has been reported [25, 26]. A prospective randomized protocol should be performed to establish if early anemia correction does modify retinopathy severity outcome and/or prevalence in those patients.

Previous studies [27, 28] have suggested that, compared with normal red cells, diabetic erythrocytes have an impaired deformability and that this may play a role in the development of diabetic microangiopathy. In the diabetic retina, once retinopathy lesions have developed, occluded capillaries are observed with impaired autoregulation of the remaining microvasculature resulting in tissue hypoxia [29, 30]. It has been suggested that hypoxia resulting from anemia, can favor the release of a vasoproliferative factor (factor I) and, hence, possibly major the tendency to develop proliferative retinopathy by impairing vascular endothelial growth factor (VEGF) production [31]. Because VEGF is a major factor in the genesis of proliferative retinopathy and is secreted in response to hypoxia stimuli, it may trigger retinal proliferation. 


\section{Renal Function}

Whether anemia correction may be beneficial to the progression of diabetic nephropathy remains unknown. One study demonstrated that the reversal of anemia by rHuEPO was able to slow down the progression of chronic kidney disease but this effect is less prominent in diabetic compared to non-diabetic patients [32]. More recently, Ueda et al. [33] have investigated factors affecting the progression of renal failure by measuring the doubling of serum creatinine as an end point in a cohort of 85 type 2 diabetic patients with chronic renal impairment. Insulin therapy, serum albumin, mean blood pressure and hemoglobin were found to be independent and significant predictors of progression towards renal failure.

In another open uncontrolled study in which 179 patients with chronic heart failure (type II diabetic 84; non diabetic 95) were treated with $\mathrm{rHuEPO}$ and iron to maintain a target hemoglobin of $12.5 \mathrm{~g} / \mathrm{dl}$ throughout the study, the mean serum creatinine and creatinine clearance (assessed with the Cockcroft and Gault formula) did not change significantly in either group during the study whereas the mean rate of fall in creatinine clearance in the period before the study (untreated anemia) was $>1 \mathrm{ml} /$ $\mathrm{min} / \mathrm{month}$ in both groups [34].

\section{Cardiovascular Disease}

No clear evidence has been reported on the effect of reversed anemia on cardiovascular risk in diabetes patients. However, diabetic patients have a higher burden of cardiovascular disease at initiation of dialysis [35]. Anemia has been identified as an important factor in the development of left ventricular hypertrophy in chronic renal failure patients [36]. Small studies suggest that anemia reversal can either induce regression or prevent the development of left ventricular hypertrophy $[37,38]$. In addition in one open uncontrolled study [34], correction of anemia (with a hemoglobin target of $12.5 \mathrm{~g} / \mathrm{dl}$ ) significantly improved left ventricular ejection fraction and NYHA score both in non-diabetic and diabetic patients.

\section{Target Hemoglobin}

Currently, there is no recommendation for a different hemoglobin target in diabetic and non-diabetic patients; a hemoglobin of $11-12 \mathrm{~g} / \mathrm{dl}$ is thus theoretically appropriate for all patients. However, some patients such as those with congestive heart failure, severe symptomatic coronary heart disease or symptomatic cerebrovascular disease may need an rHuEPO dosage allowing them to reach a hematocrit level higher than usually recommended.
Despite considerable accumulating evidence that anemia exacerbates severity of small vessel disease in many organs in diabetic patients and even though EPO therapy may favorably influence outcome, this subgroup is not considered as an exception to the standard objectives of anemia treatment.

In the latest 'Revised European Best Practice Guidelines for the Management of Anemia' [39], it is even clearly stated that until data become available, it seems reasonable to recommend a cautious approach towards raising hemoglobin concentration to levels $>12 \mathrm{~g} / \mathrm{dl}$ in patients with diabetes, especially with concurrent peripheral vascular disease. Indeed, even in the Besarab et al. [40] study and in the Scandinavian trial [41] which aimed at normalizing hemoglobin, the subgroup of diabetic patients was not analyzed separately. In the only study of normalization of hemoglobin in diabetic patients [34], only few deaths occurred precluding any analysis of mortality. In addition, one retrospective study reported an increased risk of peripheral vascular events in 85 diabetic patients treated with $\mathrm{rHuEPO}$ when compared with those not receiving the drug, even though hemoglobin levels were similar in both groups [41].

Many issues including the prevalence, the pathophysiology and the consequences of anemia in diabetic patients remain unsettled. Further prospective and controlled studies are mandatory. In this regard, the CREATE study (Effect of Anemia Correction on Cardiac Structure and Function in patients with Early Diabetic Nephropathy) and the ACORD study (Anemia Correction in Early Diabetic Nephropathy) results are urgently needed [42]. 


\section{References}

1 Ritz E, Rychlik I, Locatelli F, Halimi S: End stage renal failure in type 2 diabetes: A medical catastrophe of worldwide/ dimensions. Am J Kidney Dis 1999;34:795-808.

$\checkmark 2$ Chantrel F, Enache I, Boullier M, et al: Abysmal prognosis of patients with type 2 diabetes entering dialysis. Nephrol Dial Transplant 1999; 14:129-136.

-3 Bosman D, Winkler A, Marsden J, et al: Anemia with erythropoietin deficiency occurs early in diabetic nephropathy. Diabetes Care 2001; 24:495-499.

4 Inomata S, Itoh M, Imai H, Sato T: Serum levels of erythropoietin as a novel marker reflecting the severity of diabetic nephropathy. Nephron 1997;75:426-430.

$\checkmark 5$ Ishimura E, Okumo S, et al: Diabetes mellitus increases the severity of anemia in non dialyzed patients with renal failure. J Nephrol 1998;11:83-86.

6 Dikow R, Schwenger V, Schömig M, Ritz E: How should we manage anemia in patients with diabetes? Nephrol Dial Transplant 2002; 17(S):67-72.

$>7$ Kazmi WH, Annamaria TK, Khan S, Abichandan I, Ruthazer R, Obrador G, Pereira BJG: Anemia: An early complication of chronic renal insufficiency. Am J Kidney Dis 2001;38: 803-812.

$>8$ Valderrabano F, Hörl WH, MacDougall IC, Rossert J, Rutowski B, Wauters JP: Pre-dialysis survey on anemia management. Nephrol Dial Transplant, 2003;18:89-100.

$>9$ Jungers PY, Robino C, Choukroun G, NguyenKhoa T, Massy ZA, Jungers P: Incidence of anemia, and use of epoetin therapy in pre-dialysis patients: A prospective study in 403 patients. Nephrol Dial Transplant 2002;17:1621 1627.

-10 Thomas CM, MacIsaac RJ, Tsalamandris C, Power D, Jerums G: Unrecognized anemia in patients with diabetes. Diabetes Care 2003;26: 1164-1169.

11 Astor BC, Muntner P, Levin A, Eristace JA, Coresh J: Association of kidney function with anemia: the third national health and nutrition examination survey (1988-1994). Arch Intern Med 2002;162:1401-1408.

12 Thomas MC, MacIsaac RJ, Tsalamandris C, Molyneaux L, Gombina I, Fulchez G, Yve D, Jerums G: The Burden of anemia in type 2 diabetes and the role of nephropathy: A cross-sectional study. Nephrol Dial Transpl 2004;19: 1792-1797.

13 Stevens PE, Didonoghue DJ, Lameire NR Anemia in patients with diabetics: Unrecognized, undetected and untreated; Curr Med Res Op 200;19:395-401.

14 Takaku F, Hirasima K, Okinaka S: Effects of the bilateral section of the splanchnic nerve in erythropoiesis. Nature 1961;191:500-501.
15 Beynon G: The influence of the autonomic nervous system in the control of the erythropoietin secretion in the hypoxic rat. J Physiol 1977; 266:347-360.

16 Winkler AS, Marsden J, Chaudhuri KR, Hambley H, Watkins PJ: Erythropoietin depletion and anemia in diabetes mellitus. Diab Med 1999;16:813-819.

17 Rarick MU, Espina BM, Colley DT, Chrusoki E, Gandara S, Feinstein DI: Treatment of a unique anemia in patients with IDDM with erythropoietin-alpha. Diab Care 1998;21:423426.

18 Ricerca BM, Todaro L, Caduto S, Cotroneo P, Damiani P, Manto A, Pitocco D, Storti S, Ghirlanda G: Blunted erythropoietin response to anemia in type 1 diabetic patients disease. Blood 1992;80:1639-1647.

19 Jeffrey RF, Kendall RG, Prabhu O, Norfolk DR, Will EJ, Davison AM: Re-establishment of erythropoietin responsiveness in end-stage renal failure following renal transplantation. Clin Nephrol 1995;44:241-247.

20 Means RT, Krantz SB: Progress in understanding the pathogenesis of the anemia of chronic disease. Blood 1992;80:1639-1647.

21 Donnelly S, Shah BR: Erythropoietin deficiency in hyporeninemia. Am J Kidney Dis 1999; 33:947-953.

22 Bayes B, Serra A, Junca J, Lanzurica R: Successful treatment of anemia of nephritic syndrome with recombinant erythropoietin. Nephrol Dial Transplant 1998;13:1894-1895.

23 Qiao Q, Keinanen F, Kiukanniemi S, Laara E: The relationship between haemoglobin levels and diabetic retinopathy. $\mathrm{J}$ Clin Epidemiol 1997;50:153-158.

24 Davis M, Fisher M, Gangnon R, et al: Risk factors for high risk proliferative retinopathy study report. Invest Ophtalmol Vis Sci 1998; 39:233-252.

25 Shorb S: Anemia and diabetic retinopathy. Am J Ophthalmol 1985;100:434-436.

26 Friedman E, Brown C, Berman D: Erythropoietin in diabetic macular oedema and renal insufficiency. Am J Kidney Dis 1995;26:202208.

27 Barnes AJ, Locke P, Sendder PR, Dormandy TL, Dormangy JA, Slack J: Hyperviscosity: A treatable component of diabetic microcirculatory. Lancet 1977;15:789-902.

28 Mc Millan DE, utterback NG, Puma JL, Barbara S: Reduced erytrocytes deformability in diabetes. Diabetes 1978;27:895-901.

29 Sinclair S: Macular retinal capillary hemodynamics in diabetic patients. Ophthalmology 1991;98:1580-1586.

30 Sinclair S, Mainster M: Diabetic macular edema: New concepts of pathology and treatment (Editorial). Semin Ophthalmol 1999;14:197199.
31 Benjamin L: Glucose, VEGF-A and diabetic complications. Am J Pathol 2001;158:11811184.

32 Kuriyama S, Tomonari H, Yoshida H, Hasimoto T, Kawagushi Y, Sakai O: Reversal of anemia by erythropoietin therapy retards the progression of chronic renal failure, especially in non diabetic patients. Nephron 1997;77: 176-185.

33 Ueda I, Shoji T, Emoto M, Morioka T, Matsumoto N, Fukumoto S, Miki T, Inaba M, Nishizawa $\mathrm{Y}$ : Factors affecting progression of renal failure in patients with type 2 diabetes. Diab Care 2003;26:1530-1534.

34 Silverberg DS, Wexler D, Blum WD, Tchebiner JZ, Shops D, Keren G, Schwatz D, Baruch R, Yachnin T; Shraked M, Schwartz I, Steinbruch S, Taina A: The effect of correction of anemia in diabetics and non-diabetics with severe resistant congestive heart failure and chronic renal failure by subcutaneous erythropoietin and intravenous iron. Nephrol Dial Transplant 2003;17:141-146.

35 Foley RN: Cardiac disease in diabetic endstage renal disease. Diabetologia 1997;40: 1307-1312.

36 Levin A, Thompson CR, Ethier J, Carlisle EJ, Tobe S, Mendelsshon D, Burgess E, Jindal K, Barrett B, Singer J, Djurdjen O: Left ventricular mass index increase in early renal disease: Impact of decline in haemoglobin. Am J Kidney Dis 1999;34:125-134.

37 Portoles J: Cardiovascular effects of recombinant human erythropoietin in pre-dialysis patients. Am J Kidney Dis 1997;29:541-548.

38 Hayashi T: Cardiovascular effect of normalizing the hematocrit level during erythropoietin therapy in pre-dialysis patients with chronic renal failure. Am J Kidney Dis 2000;35:250 256.

39 Revised European Best practice guidelines for the management of anemia in patients with chronic renal failure. Nephrol Dial Transpl 2004;19(S2):ii1-ii47.

40 Besarab A, Bolton WK, Browne JK, et al: The effects of normal as compared with low hematocrit values in patients with cardiac disease who are receiving hemodialysis and epoetin. $\mathrm{N}$ Engl J Med 1998;339:584-590.

41 Furuland H, Luige T, Alhmen J, Christensson A, Strombom U, Danielson BG: A randomized controlled trial of haemoglobin normalization with erythropoietin-alpha in pre-dialysis and dialysis patients. Nephrol Dial Transplant 2003;28:353-361.

42 Laville M: New strategies in anemia management. ACORD (Anemia Correction in Diabetes) trial. Acta Diabetol 2004;41(S1):S18S22. 